\title{
Tingkat Persaingan Eksportir Utama Lada Dunia
}

\section{(Competition Level of Major World Pepper Exporters)}

\author{
Eka Miftakhul Jannah ${ }^{1{ }^{*}}$, Rita Nurmalina ${ }^{2)}$, Ratna Winandi Asmarantaka ${ }^{2)}$ \\ 1) Program Studi Agribisnis, Sekolah Pascasarjana Institut Pernanian Bogor, Jl. Kamper Wing 4 \\ Level 5 Kampus IPB Darmaga, Bogor 16680 Indonesia dan ${ }^{2)}$ Departemen Agribisnis, Fakultas \\ Ekonomi dan Manajemen Institut Pernanian Bogor, Jl. Kamper Wing 4 Level 5 Kampus IPB \\ Darmaga, Bogor 16680 Indonesia \\ E-mail: eka_eg@yahoo.com
}

\begin{abstract}
Indonesia's pepper growth rate tends to decrease compared to the growth rate of world pepper demand. This is due to the decline in production in Indonesia in recent years. This has an impact on the amount offered by Indonesia to meet the needs of the world. Indonesia's inability to compete with other countries makes Indonesia's position in taking on the growth of the world's hopes can be used by other countries. This situation can change Indonesia's position and competitiveness in trade on the international market. This study aims to analyze the level of competition between countries by using Revealed Comparative Auntungan (RCA and Dynamics Revealed Comparative Advantage (DRCA). The results of the study show that during the 2011-2013 period the highest increase in competitiveness between countries during the other period was an increase Significant exports to the countries of Brazil, India and Pakistan which increased on the value of RCA. Delaying in the 2011-2013 and 20142016 periods was related to increasing countries increasing exports such as Indonesia, Brazil and India. Position of Indonesia in 2016 Enlarging free markets greater than the results of world exports, Indonesia must increase the country's competitiveness.
\end{abstract}

Keywords: competitiveness, DRCA, market share, pepper exports, RCA

DOI: http://dx.doi.org/10.25181/jaip.v7i2.1128

Diterima: 4 Mei 2019 / Disetujui: 19 September 2019 / Diterbitkan: 28 Oktober 2019

\section{PENDAHULUAN}

Volume produksi lada Indonesia pada tahun 2011 sampai dengan tahun 2015 mengalami fluktuasi, namun jika melihat dari tren pergerakannya memperlihatkan kecenderungan meningkat dengan laju pertumbuhan rata-rata sebesar 11,92 persen setiap tahunnya. Produksi lada tertinggi Indonesia dapat terlihat pada tahun 2015, yaitu 80.000 ton. Data ini juga memperlihatkan produksi lada pada tahun 2013 sebesar 63.000 ton atau mengalami penurunan sebesar 15 persen dari tahun 2012, demikian pula pada tahun 2014 mengalami penurunan sebesar 18 persen. Situasi yang sama juga terjadi dengan volume ekspor lada Indonesia, pergerakan volume ekspor lada Indonesia dari tahun 2011 hingga 2015 juga memperlihatkan perkembangan yang fluktuatif. Volume ekspor lada tertinggi Indonesia tercatat pernah tercapai pada tahun 2012 sebesar 62.608 ton, sehingga pada tahun tersebut merupakan pencapaian peningkatan volume ekspor lada tertinggi Indonesia, yaitu sebesar 72 persen. Rata-rata proporsi volume ekspor lada Indonesia terhadap total produksinya mencapai 34 
persen. Situasi ini menunjukkan tingginya konsentrasi Indonesia untuk memasok produksi ladanya untuk pemenuhan kebutuhan lada dunia. Secara terinci perkembangan perkembangan produksi dan ekspor lada Indonesia tercantum pada Gambar 1.

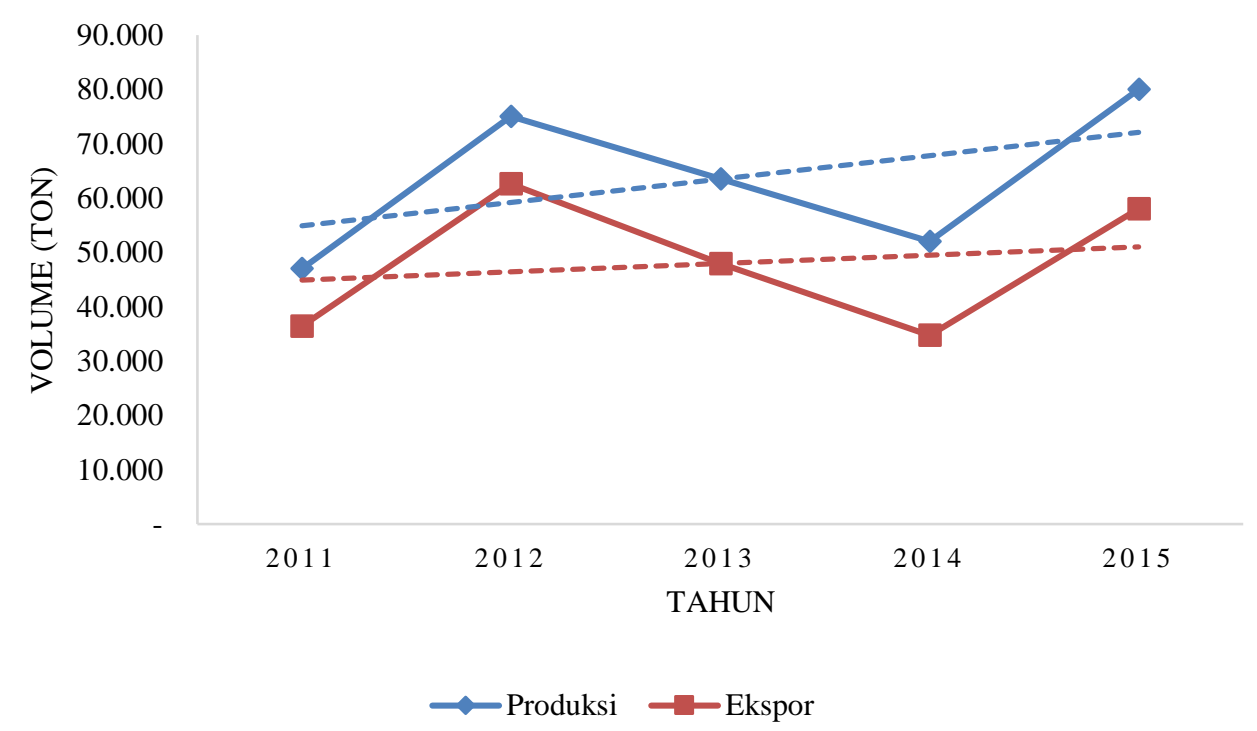

Gambar 1. Perkembangan volume produksi dan ekspor lada Indonesia tahun 2011-2015 Sumber: IPC, 2017 (diolah)

Apabila dievaluasi, terdapat fenomena dimana tren ekspor lada Indonesia menunjukkan pertumbuhan yang kurang berkembang. Hal ini dapat terlihat bahwa meskipun tren pergerakan ekspor lada Indonesia menunjukkan peningkatan, namun laju pertumbuhan rata-ratanya ternyata lebih rendah daripada laju pertumbuhan rata-rata volume produksinya, dimana laju pertumbuhan rata-rata volume ekspor sebesar 9,22 persen per tahun. Seharusnya, laju pertumbuhan lada Indonesia yang cukup tinggi (11,92 persen) serta tingkat konsumsi lada dalam negeri yang rendah bisa memberikan peluang untuk mendorong volume ekspor lada Indonesia semakin meningkat.

Situasi pertumbuhan ekspor yang kurang berkembang ini akan memengaruhi terhadap pangsa ekspor lada Indonesia di pasar internasional yang berfluktuasi pada setiap tahunnya sehingga menjadikan Indonesia sebagai negara eksportir lada terbesar kedua di dunia, meskipun dari sisi produksi seharusnya Indonesia berpotensi memperoleh hasil yang lebih baik (Baroh et al., 2014). Ada berbagai faktor dugaan yang melatarbelakangi kurang berkembangnya ekspor lada Indonesia, salah satunya adalah berupa daya saing lada Indonesia di pasar dunia. Daya saing yang lemah atau kuat terhadap suatu produk di pasar internasional akan memberikan pengaruh terhadap besar atau kecilnya volume ekspor komoditas tersebut (Krugman \& Obstfeld, 2005; Salvatore, 1997).

Salah satu upaya untuk meningkatkan ekspor lada Indonesia adalah dengan meningkatkan kualitas dan daya saing terhadap komoditas ekspor tersebut, sehingga diharapkan kedepan ekspor lada Indonesia dapat mengimbangi atau bahkan mengalahkan negara pesaing. Selain itu, daya saing dan perdagangan lada Indonesia juga dipengaruhi oleh perilaku dan kinerja negara pesaing lainnya. 
Saat ini, selain berupaya meningkatkan kapasitas produksi lada dalam negerinya, beberapa negara produsen lada ini juga terlihat begitu gencarnya berupaya meningkatkan kualitas lada dengan memberikan nilai tambah terhadap produk lada, sehingga produk lada negara tersebut dapat diterima dengan baik oleh pasar bahkan bila perlu mengambil alih pangsa pasar negara eksportir lainnya. Situasi ini patut diwaspadai oleh Indonesia sebagai salah satu eksportir lada terbesar di dunia untuk terus berupaya mendorong kualitas lada nasional agar lebih berdaya saing di pasar internasional.

Selain mendorong peningkatan kualitas lada, negara lainnya seperti Vietnam juga memiliki kemampuan ekspor yang jauh lebih besar dari Indonesia selama 15 tahun terakhir, serta beberapa negara eksportir lainnya yang berpotensi untuk terus meningkatkan volume ekspornya, sehingga tentunya memiliki peluang untuk merebut pangsa ekspor lada Indonesia kedepan (Tambunan, 2001). Adanya kompetisi perdagangan yang tinggi akan membuat setiap negara berupaya membuat strategi kebijakan yang tepat agar dapat bertahan hidup di tingkat persaingan yang semakin sulit (Hamdy, 2001). Vietnam merupakan negara pesaing utama Indonesia dalam memperebutkan pangsa pasar lada dunia. Tentunya ini bisa menjadi ancaman serius karena pasar ekspor Indonesia dan Vietnam memilliki kecenderungan yang sama, yaitu dibeberapa negara maju seperti di Amerika Serikat, pasar Eropa, dan beberapa di negara Asia. Sama seperti Indonesia, Vietnam merupakan salah satu produsen lada terbesar di dunia, bahkan produksi lada Vietnam jauh lebih tinggi dari Indonesia. Berdasarkan kondisi tersebut, penting untuk menganalisis tingkat persaingan dan posisi negara-negara pengekspor utama dalam dinamika waktu. Selain itu, perlu dilakukan upaya strategis untuk meningkatkan daya saing suatu negara melalui berbagai rekomendasi kebijakan.

\section{METODE PENELITIAN}

Penelitian ini akan menganalisis daya saing perdagangan lada dunia terhadap negara-negara penghasil utama lada dunia seperti Vietnam, Indonesia, Brazil, India, dan Malaysia. Penelitian ini menggunakan metode Revealed Comparative Advantage (RCA) untuk menganalisis tingkat daya saing lada suatu negara. Perubahan daya saing dapat mempengaruhi perubahan posisi pasar ekspor suatu negara sehingga dianalisis menggunakan Dynamic Revealed Comparative Advantage (DRCA). Data yang digunakan adalah data time series antara 2002-2016 yang mencakup 5 negara pengekspor kopi utama dunia. Sumber data diperoleh dari International Trade Center (ITC, 2017) dan International Pepper Community (IPC, 2017).

Tingkat jumlah suatu ekspor negara mencerminkan keunggulan komparatif suatu negara. Salah satu cara menentukan hal ini dengan menggunakan Revealed Comparative Advantage (RCA) atau index Balassa (Balassa, 1965). Semakin tinggi nilai RCA dapat menunjukkan keunggulan komparatif terhadap komoditas tertentu pada suatu negara. Ini dapat ditunjukkan dengan nilai RCA yang lebih besar dari satu. Sebaliknya jika kurang dari satu, maka komoditas tersebut tidak memiliki 
keunggulan komparatif. Kesimpulannya nilai RCA adalah $0<\mathrm{RCAij}<\infty$. Itu bisa dilihat pada persamaan 1.

$$
R C A_{j}=\frac{X_{i j} / X_{i t}}{X_{w j} / X_{w t}}
$$

Dimana:

$\mathrm{RCA}_{\mathrm{j}}=$ Daya saing suatu negara terhadap terhadap suatu komoditas $\mathrm{j}$

$\mathrm{X}_{\mathrm{ij}} \quad=$ Nilai ekspor komoditas $\mathrm{j}$ dari negara $\mathrm{i}$ (US\$)

$\mathrm{X}_{\mathrm{it}} \quad=$ Total nilai ekspor seluruh komoditas dari negara $\mathrm{i}$ (US\$)

$\mathrm{X}_{\mathrm{w} j} \quad=$ Total ekspor komoditas $\mathrm{j}$ dari seluruh negara (world) (US\$)

$X_{w t} \quad=$ Total ekspor seluruh komoditas dari seluruh negara (world) (US\$)

Secara umum, nilai RCA berada pada $0 \leq \mathrm{RCA}_{i j} \leq \mathrm{O}$, Jika nilai $\mathrm{RCA}_{\mathrm{ij}}$ lebih besar dari satu diartikan bahwa negara i memiliki daya saing lada karena pangsa komoditas j didalam ekspor total negara i lebih besar dari komoditas yang sama dalam ekspor dunia, sehingga berspesialisasi di komoditas tersebut. Sebaliknya jika kurang dari satu maka mengindikasikan negara i tidak memiliki daya saing lada sehingga tidak berspesialisasi di kelompok komoditas tersebut. Secara lebih rinci kekuatan daya saing internasional yang ditunjukkan oleh Balassa RCA Index dkelompokkan menjadi empat klasifikasi (Erkan \& Yildirimci, 2015; Hinloopen \& Onderstal, 2010):

Klasifikasi 1: $0<\mathrm{RCA}_{\mathrm{ij}} \leq 1$, tidak berdaya saing

Klasifikasi 2: $1<\mathrm{RCA}_{\mathrm{ij}} \leq 2$, daya saig lemah

Klasifikasi 3: $2<\mathrm{RCA}_{\mathrm{ij}} \leq 4$, daya saing medium

Klasifikasi 4: $4>\mathrm{RCA}_{\mathrm{ij}}$, daya saing kuat

Perubahan daya saing komoditas di suatu negara selama pada periode tertentu dapat menentukan posisi komoditas di perdagangan dunia. Situasi ini dapat dianalisis dengan menggunakan Dynamic Revealed Comparative Advantage (DRCA) (Edwards \& Schoer, 2002). Rumus DRCA dapat ditemukan dalam persamaan 2 dan 3.

$$
\begin{aligned}
D R C A & =\frac{\Delta R C A_{j}}{R C A_{j}} \ldots \ldots \ldots \ldots \ldots \ldots \ldots \ldots \ldots \ldots \ldots \ldots \ldots \ldots \ldots \ldots \ldots \ldots \ldots \ldots \ldots \\
D R C A & =\frac{\Delta\left[X_{i j} / \sum j X_{i j}\right]}{X_{i j} / \sum j X_{i j}}-\frac{\Delta\left[X_{w j} / \sum j X_{w j}\right]}{X_{w j} / \sum j X_{w j}}
\end{aligned}
$$

Dimana:

$\mathrm{RCA}_{\mathrm{j}}=$ Daya saing suatu negara terhadap komoditas $\mathrm{j}$

DRCA $=$ RCA dinamis

$\mathrm{X}_{\mathrm{ij}} \quad=$ Total ekspor komoditas $\mathrm{j}$ dari negara $\mathrm{i}$ (US\$)

$\mathrm{X}_{\mathrm{wj}} \quad=$ Total ekspor komoditas $\mathrm{j}$ dari seluruh negara (world) (US\$)

$\sum j X_{i j} \quad=$ Total ekspor seluruh komoditas dari negara i (US\$)

$\sum j X_{w j}=$ Total ekspor seluruh komoditas dari seluruh negara (world) (US\$)

$\mathrm{j} \quad=$ Komoditas $\mathrm{j}$ 


$$
\mathrm{i} \quad=\text { Negara } \mathrm{i}
$$

Penelitian Edwards dan Schoer (2002) telah menganalisa tentang dinamika posisi pasar ekspor suatu negara dengan membagi menjadi enam kategori, yaitu rising star, falling stars, lagging retreat, lost opportunity, leading retreat, dan lagging opportunity. Dari keenam kategori, posisi yang paling menguntungkan suatu negara pada kondisi rising stars dan sebaliknya yang paling merugikan adalah saat berada pada lost opportunity. Oleh karena itu, secara perspektif dinamis, maka keberhasilan restrukturisasi ekspor dapat tercermin pada pergeseran ekspor dari pasar yang mengalami stagnan (leading retreat) dan memasuki pasar yang dinamis (rising stars). Dinamika posisi pasar ekspor dapat dilihat pada Tabel 1.

Tabel 1. Dinamika posisi pasar ekspor

\begin{tabular}{|c|c|c|c|c|c|}
\hline $\mathrm{RCA}^{\mathrm{a})}$ & $\begin{array}{l}\text { Pangsa j pada } \\
\text { ekspor negara a) }\end{array}$ & & $\begin{array}{l}\text { Pangsa j pada } \\
\text { ekspor dunia a) }\end{array}$ & Posisi pasar ${ }^{\text {a) }}$ & Evaluasi ekspor ${ }^{\mathrm{ab})}$ \\
\hline \multirow[t]{2}{*}{ Naik } & $\uparrow$ & $>$ & $\uparrow$ & Rising Star & $\begin{array}{l}\text { Succesful } \\
\text { restructuring }\end{array}$ \\
\hline & $\uparrow$ & $>$ & $\downarrow$ & Falling Stars & Poor restructuring \\
\hline \multirow{4}{*}{ Turun } & $\downarrow$ & $>$ & $\downarrow$ & Lagging Retreat & Poor restructuring \\
\hline & $\downarrow$ & $<$ & $\uparrow$ & Lost Opportunity & $\begin{array}{l}\text { Poor restructuring } \\
\text { Succesful }\end{array}$ \\
\hline & $\downarrow$ & $<$ & $\downarrow$ & Leading Retreat & restructuring \\
\hline & $\uparrow$ & $<$ & $\uparrow$ & Lagging Opportunity & Poor restructuring \\
\hline
\end{tabular}

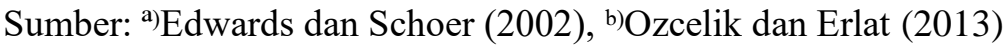

\section{HASIL DAN PEMBAHASAN}

\section{Daya Saing Lada}

Penelitian ini menganalisis daya saing lada dalam bentuk biji dengan kode HS 090411 yang diukur menggunakan analisis Revealed Comparative Advantage (RCA). Pada tabel 2 menunjukkan hasil bahwa kelima negara produsen lada utama dunia memiliki daya saing. Kondisi tersebut ditunjukkan dengan nilai RCA kelima negara yang berada di atas satu.

Vietnam merupakan negara yang memiliki nilai RCA tertinggi diantara produsen lada lainnya. Nilai RCA Vietnam yang paling tinggi diperkuat dengan konsentrasi ekspor lada dalam negeri Vietnam dibandingkan komoditas lainnya yang mencapai 57 persen, sehingga wajar menjadikan negara tersebut menjadi negara yang memiliki pangsa pasar lada tertinggi di pasar dunia. Sedangkan Indonesia hanya 15 persen dengan nilai RCA Indonesia yang mencapai 18,2 sehingga pasang ekspor lada Indonesia masih berada di bawah pencapaian Vietnam. Nilai ekspor lada Vietnam pada tahun 2016 mencapai 1.233.929 US\$ atau 157.565 ton. Sedangkan Indonesia hanya mengekspor lada ke pasar dunia dengan nilai 416.581 US\$ atau 51.759 ton. Mesikipun lada Vietnam 
memiliki daya saing, namun keseluruhan kinerja ekspor Vietnam memiliki tantangan di pasar internasional, seperti kelebihan penggunaan pestisida yang menyebabkan beberapa negara importir lada Eropa dan Asia menolak atau mengurangi ketergantungan terhadap konsumsi lada Vietnam (CBI, 2019). Sedangkan Indonesia memiliki permasalahan terhadap produktivitas lada petani yang masih rendah sehingga berdampak terhadap terganggunya kinerja ekspor lada Indonesia di pasar internasional (IPC, 2017).

Tabel 2. Nilai RCA negara eksportir utama lada dunia

\begin{tabular}{cccccc}
\hline Tahun & Vietnam & Indonesia & Brazil & India & Malaysia \\
\hline 2002 & 89,59 & 21,26 & 13,19 & 8,80 & 4,97 \\
2003 & 86,05 & 25,31 & 12,87 & 6,43 & 4,62 \\
2004 & 116,77 & 15,65 & 12,87 & 4,94 & 4,52 \\
2005 & 113,30 & 16,39 & 9,50 & 5,65 & 4,70 \\
2006 & 92,70 & 15,12 & 11,75 & 7,72 & 4,13 \\
2007 & 85,47 & 18,28 & 11,05 & 10,35 & 4,03 \\
2008 & 75,35 & 22,26 & 8,94 & 7,78 & 3,50 \\
2009 & 82,99 & 18,25 & 9,11 & 4,29 & 3,51 \\
2010 & 70,58 & 21,81 & 7,53 & 3,55 & 3,78 \\
2011 & 73,91 & 11,52 & 8,69 & 5,49 & 3,99 \\
2012 & 56,95 & 20,78 & 7,51 & 3,11 & 2,80 \\
2013 & 53,01 & 16,92 & 7,57 & 3,53 & 3,10 \\
2014 & 50,46 & 13,05 & 9,70 & 2,73 & 3,50 \\
2015 & 36,48 & 19,18 & 9,86 & 4,23 & 3,23 \\
2016 & 42,72 & 17,63 & 8,14 & 2,31 & 3,19 \\
\hline Rata-rata & 75,09 & 18,23 & 9,88 & 5,39 & 3,84 \\
\hline
\end{tabular}

Sumber: ITC (2017)

Berdasarkan Tabel 3, negara-negara yang memiliki daya saing kuat adalah Vietnam, Indonesia, Brazil, dan India. Hal ini ditunjukkan dengan nilai RCA yang lebih besar dari empat. Sedangkan negara yang memiliki daya saing medium adalah Malaysia karena memiliki nilai RCA di bawah empat. Oleh karena itu, kekuatan daya saing pada setiap negara produsen dan eksportir utama lada dunia lebih ditentukan oleh banyaknya lada yang diekspor ke pasar dunia relatif terhadap ekspor 
seluruh komoditas setiap negara. Kondisi kelima negara eksportir telah melakukan spesialiasi terhadap komoditas lada meskipun fakta di lapangan menunjukkan adanya dinamika atau perubahan terhadap kekuatan pasar ekspor.

Tabel 3. Nilai RCA negara eksportir utama lada dunia

\begin{tabular}{ll}
\hline \multicolumn{1}{c}{ Kategori } & \multicolumn{1}{c}{ Negara } \\
\hline Daya saing kuat & Vietnam, Indonesia, Brazil, India \\
Daya saing medium & Malaysia \\
\hline
\end{tabular}

Sumber: ITC (2017)

Berdasarkan Gambar 2, rata-rata pertumbuhan RCA pertahun mengalami fluktuasi. Ratarata pertumbuhan RCA Vietnam, Brazil, India, dan Malaysia mengalami penurunan selama periode 2002-2016. Penurunan RCA terbesar dialami oleh Vietnam dalam kurun waktu tersebut, meskipun pertumbuhan volume ekspor lada Vietnam cenderung mengalami peningkatan sebesar 11,54 persen per tahun. Penyebab turunnya nilai RCA di Vietnam diduga karena pangsa ekspor lada terhadap seluruh komoditas yang diekspor lebih kecil di bandingkan dengan negara pesaing lainnya. Sedangkan penurunan RCA pada beberapa tahun terakhir di beberapa produsen lada utama lainnya disebabkan oleh banyak faktor, antara lain permasalahan cuaca dan penyakit lada (IPC, 2017), adanya kebijakan tarif yang berdampak terhadap menurunnya jumlah ekspor (Kustiari \& Dermoredjo, 2017), dan adanya perubahan terhadap nilai tukar riil, harga ekspor, kebijakan devaluasi, dan pendapatan dunia (Utomo, 2012; Gebre, 2015).

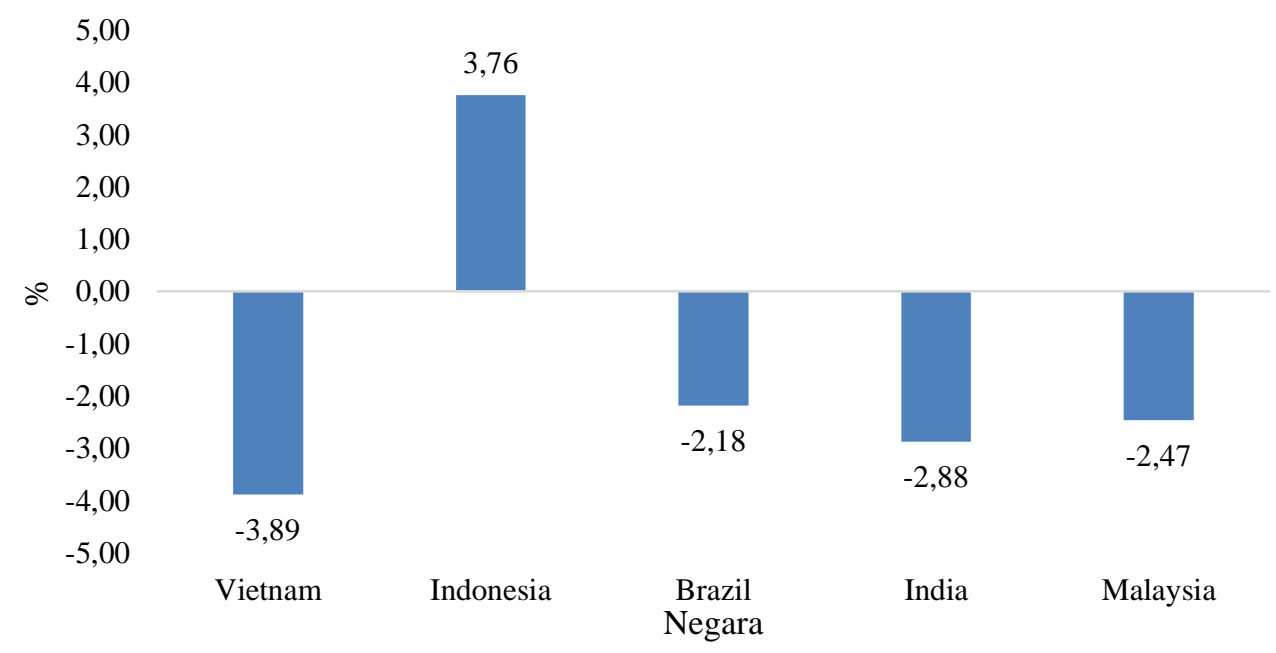

Gambar 2. Nilai rata-rata pertumbuhan RCA negara eksportir utama lada dunia Sumber: ITC, 2017 diolah

Sementara itu, satu-satunya negara yang mengalami peningkatan RCA adalah Indonesia, yaitu sebesar 3,76 persen per tahun. Hal ini juga dikuti dengan pertumbuhan ekspor lada Indonesia 
yang terus meningkat sebesar 5,01 persen per tahun selama periode tahun 2002-2006. Dengan karakteristik jenis lada yang diekspor serupa dengan Vietnam, rata-rata pertumbuhan RCA per tahun lada Indonesia lebih tinggi daripada Vietnam. Namun pada tahun 2016, pertumbuhan ekspor lada Indonesia mengalami penurunan sebesar 30,94 persen. Jika dibandingkan dengan pesaing utama yang memiliki karakter lada yang sama, pangsa pasar Vietnam masih hampir 4 kali lebih tinggi dari pangsa pasar Indonesia selama tahun 2002-2016. Sedangkan pada tahun 2016, pangsa pasar Vietnam hampir 2,5 kali ebih tinggi dari pangsa pasar Indonesia. Hal ini menunjukkan bahwa meskipun ratarata pertumbuhan RCA Vietnam negatif namun pangsa lada Vietnam masih lebih besar daripada pangsa lada Indonesia di pasar internasional. Hal utama yang memengaruhi meningkatnya daya saing komoditas pertanian Vietnam karena faktor produksi (seperti kondisi alam, kualitas sumberdaya manusia, kemudahan permodalan), kondisi keamanan nasional yang kondusif, tersedianya agroindustri dan sarana pendukung terkait ekspor, kebijakan perusahaan, tingkat persaingan, dukungan pemerintah, dan penciptaan peluang pasar (Nhien, 2016). Meskipun demikian, kualitas lada Indonesia lebih disukai di pasar internasional karena memiliki kandungan residu pestisida yang berada di bawah diambang batas ekspor.

Sebenarnya, Indonesia memiliki keunggulan kualitas lada dan luas tanam lada yang lebih baik dari Vietnam (Kementerian Pertanian, 2015). Namun demikian, keunggulan ini belum mampu dikembangkan secara maksimal sehingga produktivitas lada nasional masih rendah. Untuk meningkatkan kemampuan ekspor lada yang masih rendah Indonesia perlu memberikan jaminan stabilitas harga lokal, mengurangi resiko terhadap biaya transaksi yang tinggi dengan memperpendek panjangnya rantai pasok dan berbagai pemain dalam proses ekspor, memberikan edukasi kepada stakeholder dalam upaya meningkatkan pengawasan kualitas, meningkatkan produktivitas, dan menutup penyelundupan (Boansi \& Crentsil, 2013). Jika hal ini dapat diperbaiki, maka minat petani untuk meningkatkan produktivitas lada diharapkan akan semakin meningkat sehingga dapat meningkatkan nilai daya saing lada Indonesia.

\section{Dinamika RCA tiap negara eksportir utama lada dunia}

Pertumbuhan rata-rata RCA yang mengalami penurunan ditemukan di Vietnam, Indonesia, Brazil, India dan Malaysia. Tingkat penurunan tertinggi diperoleh oleh India sebanyak 64 persen selama periode 2008 hingga 2010. Pada periode 2011-2013 juga mengalami penurunan yang rendah sebanyak 43 persen. Kondisi ini disebabkan oleh adanya anomali cuaca dan gangguan hama penyakit terhadap tanaman lada yang belum ada penyelesaian hingga sekarang (IPC, 2017).

Tingginya nilai RCA yang diperoleh oleh Vietnam disebabkan oleh pangsa pasar ekspor lada terhadap semua komoditas ekspor negara tersebut yang lebih tinggi dibandingkan dengan negara lain. Daya saing eksportir lada utama dunia menunjukkan perubahan selama periode waktu tertentu. 
Secara umum, pertumbuhan pangsa pasar ekspor lada dari eksportir lada utama dalam lima belas tahun terakhir lebih rendah daripada pertumbuhan pangsa pasar lada dunia.

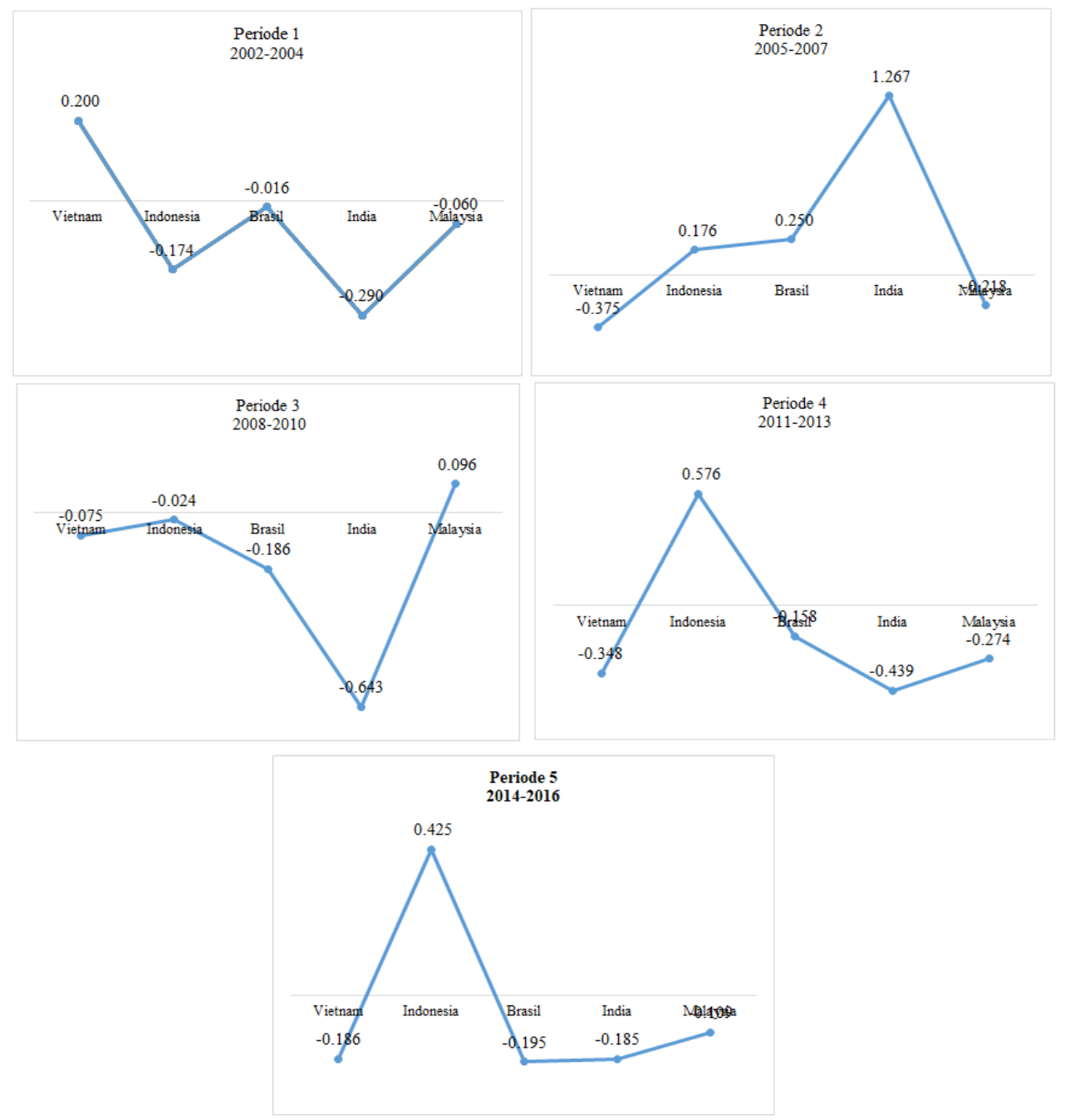

Gambar 3. Dinamika RCA (DRCA) pada eksportir utama lada dunia pada lima periode waktu Sumber: ITC (2017) (diolah)

Penelitian ini membagi waktu penelitian dalam lima periode waktu untuk memudahkan melihat pergerakan yang terjadi dalam setiap periode (Rosiana et al., 2017). Hasil temuan pada Gambar 3 menunjukkan selama periode kesatu (2002-2004), pertumbuhan ekspor lada Vietnam adalah yang tertinggi dari Indonesia, Brazil, India dan Malaysia. Sementara India memiliki pertumbuhan yang terendah karena pertumbuhan pangsa pasar ekspor India yang sedang mengalami penurunan secara signifikan selama periode tersebut.

Namun sebaliknya dengan periode kedua (2005-2007), dimana pertumbuhan ekspor lada India meningkat lebih tinggi dari negara-negara lain. Sedangkan Vietnam mengalami pertumbuhan pangsa pasar lada yang lebih rendah daripada pangsa pasar dunia dikarenakan nilai perdagangan lada yang diekspor mengalami penurunan secara signifikan. Indonesia, Brazil dan Malaysia menjadi tiga 
negara yang mengalami pertumbuhan ekspor yang meningkat selama periode kedua karena memiliki pangsa ekspor yang lebih tinggi daripada pangsa pasar dunia.

Pada periode 2008-2010, India kembali mengalami pertumbuhan ekspor yang lebih rendah daripada keempat negara eksportir lainnya, bahkan penurunan ekspor India menjadi yang terendah dalam lima periode terakhir. Situasi ini menjadikan ekspor lada India mengalami fluktuasi yang paling signifikan dibandingkan dengan keempat produsen utama lada lainnya. Berbeda dengan Malaysia, selama periode ketiga ini, pertumbuhan ekspor Malaysia menjadi satu-satunya negara yang menunjukan pertumbuhan ekspor yang positif dibandingkan pangsa pasar dunia. Kondisi ekspor lada Indonesia selama periode ini mengalami pertumbuhan RCA yang menurun sebesar -0.024 yang disebabkan oleh pertumbuhan pangsa ekspor lada Indonesia yang lebih rendah daripada pangsa pasar dunia.

\section{Perubahan Posisi Persaingan Tiap Negara Eksportir Utama Lada Dunia}

Penjelasan hasil DRCA pada Gambar 3 belum mampu menjelaskan secara menyeluruh terhadap situasi yang terjadi dalam perdagangan lada nasional. Maka dari itu, Tabel 4 akan menjelaskan perbandingan antara tingkat pertumbuhan pangsa pasar lada suatu negara dengan tingkat pertumbuhan pangsa pasar dunia. Perbandingan terhadap kedua pangsa pasar tersebut nantinya diharapkan bisa menjelaskan tentang dinamika posisi pasar persaingan perdagangan lada antara negara penghasil utama lada dunia dalam lima periode waktu.

Tabel 4. Nilai RCA negara eksportir utama lada dunia

\begin{tabular}{|c|c|c|c|c|c|c|}
\hline \multirow{2}{*}{ No. } & \multirow{2}{*}{ Negara } & Periode 1 & Periode 2 & Periode 3 & Periode 4 & Periode 5 \\
\hline & & $2002-2004$ & $2005-2007$ & $2008-2010$ & $2011-2013$ & $2014-2016$ \\
\hline 1 & Vietnam & Failing stars & $\begin{array}{c}\text { Lagging } \\
\text { opportunity }\end{array}$ & $\begin{array}{c}\text { Leading } \\
\text { retreat }\end{array}$ & $\begin{array}{c}\text { Lost } \\
\text { opportunity }\end{array}$ & Failing stars \\
\hline 2 & Indonesia & $\begin{array}{l}\text { Lagging } \\
\text { retreat }\end{array}$ & Rising stars & Rising stars & $\begin{array}{c}\text { Lost } \\
\text { opportunity }\end{array}$ & $\begin{array}{l}\text { Lagging } \\
\text { retreat }\end{array}$ \\
\hline 3 & Brasil & $\begin{array}{l}\text { Lagging } \\
\text { retreat }\end{array}$ & $\begin{array}{c}\text { Lagging } \\
\text { opportunity }\end{array}$ & $\begin{array}{c}\text { Lost } \\
\text { opportunity }\end{array}$ & Rising stars & $\begin{array}{c}\text { Lagging } \\
\text { retreat }\end{array}$ \\
\hline 4 & India & $\begin{array}{l}\text { Lagging } \\
\text { retreat }\end{array}$ & Rising stars & $\begin{array}{c}\text { Lost } \\
\text { Opportunity }\end{array}$ & Rising stars & $\begin{array}{c}\text { Lagging } \\
\text { retreat }\end{array}$ \\
\hline 5 & Malaysia & $\begin{array}{l}\text { Lagging } \\
\text { retreat }\end{array}$ & $\begin{array}{c}\text { Lagging } \\
\text { opportunity }\end{array}$ & Rising stars & Rising stars & $\begin{array}{c}\text { Lagging } \\
\text { retreat }\end{array}$ \\
\hline
\end{tabular}

Sumber: ITC (2017) 
Pada periode pertama (2002-2004), ada beberapa negara yang dianggap mencapai posisi lagging retreat, yaitu Indonesia, Brazil, Malaysia dan India. Dalam kondisi itu, penurunan pangsa lada di masing-masing negara lebih tinggi dibandingkan dengan pangsa lada dunia. Posisi ini adalah posisi yang paling tidak diharapkan oleh masing-masing negara eksportir dalam menghadapi situasi persaingan antar negara. Selama periode ini, Vietnam juga menghadapi situasi yang merugikan karena peningkatan pangsa lada yang lebih tinggi daripada penurunan pangsa lada dunia.

Berbeda dengan periode sebelumnya, selama periode kedua (2005-2007), Indonesia dan India ternyata mampu memperbaiki kinerja ekspor ladanya sehingga memengaruhi peningkatan RCA kedua negara itu dibandingkan dengan periode sebelumnya. Kondisi ini menyebabkan Indonesia dan India berada pada posisi rising stars. Dalam kondisi ini, pangsa lada di masing-masing negara lebih tinggi dari pangsa lada dunia. Posisi ini adalah posisi yang paling diharapkan oleh masing-masing negara dalam menghadapi persaingan perdagangan antara negara eksportir. Selain itu, kedua negara tersebut berusaha meningkatkan pangsa pasar melalui peningkatan kualitas. Peningkatan kualiatas lada akan memengaruhi terhadap permintaan pasar ekspor dan konsumsi domestik (Arifin, 2013). Nilai DRCA tertinggi diantara ketiga negara adalah India dengan nilai 1,266 dan diperkuat dengan pertumbuhan volume ekspor India yang meningkat sebesar 72 persen pada periode kedua. Sementara Vietnam, Brazil dan Malaysia mengalami kondisi lagging opportunity karena peningkatan pangsa lada di masing masing negara tersebut lebih rendah dari pangsa lada dunia.

Indonesia masih mampu mempertahankan posisi rising stars hingga periode ketiga (20082010) bersama-sama dengan Malaysia. Sedangkan Brasil dan India berada pada posisi lost opportunity. Kondisi ini disebabkan karena kedua negara tersebut tidak mampu memanfaatkan peluang disaat pertumbuhan pangsa lada dunia sedang megalami penurunan. Kondisi ini dapat terlihat dari menurunnya pertumbuhan pangsa lada Brazil dan India. Sementara Vietnam berada di kondisi lagging opportunity. Dalam kondisi ini, pertumbuhan pangsa kopi Vietnam masih lebih rendah dari pertumbuhan pangsa lada dunia.

Selama periode keempat (2011-2013), Indonesia adalah negara yang mengalami penurunan RCA dibandingkan dengan periode sebelumnya. Dalam kondisi ini, Indonesia tidak mampu memanfaatkan peluang disaat pangsa lada dunia sedang menunjukkan peningkatan. Posisi ini menyebabkan Indonesia berada pada posisi lost opportunity. Kondisi ini dikuti juga oleh Malaysia yang berada pada posisi yang sama dengan Indonesia. Sementara Brazil, India, dan Malaysia berhasil memanfaatkan peluang dengan meningkatkan pangsa lada melebihi daripada pangsa lada dunia. Dalam kondisi ini menyebabkan Brazil, India, dan Malaysia berada pada posisi rising stars. Ini menunjukkan bahwa negara-negara tersebut mampu mengambil kesempatan untuk meningkatkan pangsa pasar mereka.

Pada periode kelima (2014-2015), ada beberapa negara yang mengalami lagging retreat, yaitu Indonesia, Brazil, India, dan Malaysia. Posisi pasar ini merupakan posisi yang paling tidak 
diharapkan masing-masing negara eksportir. Dalam kondisi itu, pertumbuhan pangsa lada memiliki nilai yang lebih rendah dari penurunan pangsa lada dunia. Sementara itu Vietnam berada pada kondisi failing stars. Situasi ini mencerminkan bahwa pangsa lada Vietnam yang meningkat seharusnya mampu memberikan kesempatan Vietnam untuk meraih keuntungan yang lebih besar, namun karena kondisi pangsa pasar lada dunia yang menurun membuat kesempatan Vietnam untuk mendapat keuntungan yang lebih besar menjadi hilang. Meskipun posisi pasar Indonesia cenderung mengalami pergeseran ke posisi yang tidak menguntungkan, namun setidaknya pertumbuhan pangsa ekspor lada Indonesia masih memiliki potensi untuk terus ditingkatkan, hal ini dibuktikan dengan pertumbuhan RCA yang masih terus meningkat dan pernah mencapai posisi rising stars selama dua periode.

\section{KESIMPULAN DAN SARAN}

\section{Kesimpulan}

Berdasarkan hasil analisis di pembahasan sebelumnya bisa menjadi informasi yang sangat penting dalam memberikan saran kebijakan bagi Indonesia upaya meningkatkan perdagangan lada di pasar internasional. Hasil analisis daya saing menunjukkan bahwa ekspor lada Indonesia memiliki daya saing di pasar internasional, terbukti dengan nilai RCA yang memiliki nilai lebih besar dari satu. Selain itu, kemampuan daya saing lada Indonesia juga berkategori kuat karena memiliki nilai RCA lebih besar dari empat. Hal ini diperkuat dengan dengan hasil analisis dinamika daya saing lada Indonesia yang berpotensi untuk terus ditingkatkan karena pernah berhasil berada pada posisi rising stars pada periode 2005-2007 dan periode 2008-2010, artinya pertumbuhan pangsa ekspor Indonesia masih lebih tinggi dari pertumbuhan pangsa ekspor dunia. Kondisi ini memberikan gambaran bahwa ekspor lada Indonesia masih berpotensi untuk terus ditingkatkan di masa mendatang dengan menaikkan kualitas dan kuantitas produksi lada nasional.

\section{Saran}

Untuk meningkatkan kemampuan ekspor lada yang masih rendah Indonesia perlu memberikan jaminan stabilitas harga lokal, mengurangi resiko terhadap biaya transaksi yang tinggi dengan memperpendek panjangnya rantai pasok dan berbagai pemain dalam proses ekspor, memberikan edukasi kepada stakeholder dalam upaya meningkatkan pengawasan kualitas, meningkatkan produktivitas, dan menutup penyelundupan. Jika hal ini dapat diperbaiki, maka minat petani untuk meningkatkan produktivitas lada diharapkan akan semakin meningkat sehingga dapat meningkatkan nilai daya saing lada Indonesia. 


\section{UCAPAN TERIMA KASIH}

Penulis mengucapkan terima kasih kepada semua pihak yang telah membantu dalam penelitian ini, terutama kepada Badan Litbang Pertanian yang telah membantu dalam pendanaan selama penelitian. Kedua, kepada Dr. A. Arifin Rivaie selaku pimpinan BPTP Lampung yang telah memberikan kesempatan penulis untuk melanjutkan studi. Ketiga kepada International Pepper Community (IPC) atas bantuan penyediaan data yang dibutuhkan penulis. Semoga artikel ini dapat memberikan manfaat bagi masyarakat.

\section{DAFTAR PUSTAKA}

Arifin, B. (2013). On the competitiveness and sustainability of the Indonesian agricultural export commodities. ASEAN Journal of Economics, Management and Accounting, 1(1), 81-100.

Balassa, B. (1965). Trade lberalization and revealed comparative advantage. The Manchaster School of Economic and Sosial Studies, 33, 92-123.

Baroh, I., Hanani, N., Setiawan, B., \& Koestiono, D. (2014). Indonesian coffee competitiveness in the International Market: Armington Model Application. American Journal of Economics, 4(4), 184-194.

Boansi, D., \& Crentsil, C. (2013). Competitiveness and Determinants of Coffee Exports, Producer Price and Production for Ethiopia. Journal of Advanced Research in Economics and International Business, 1(1), 31-56.

CBI. (2019). Which trends offer opportunities on the European spices and herbs market? Retrieved October 14, 2019, from https://www.cbi.eu/node/2913/pdf/.

Edwards, L., \& Schoer, V. (2002). Measures of competitiveness: a dynamic approach to South Africa's trade performance in the 1990s. South African Journal of Economics, 70(6), 1008-1046.

Erkan, B., \& Yildirimci, E. (2015). Economic Complexity and Export Competitiveness: The Case of Turkey. Procedia-Social and Behavioral Sciences, 195, 524-533.

Gebre, Y. (2015). Determinants of Coffee Export Performance in Ethiopia. Journal of Economics and Sustainable Development, 6(5), 147-157.

Hamdy, H. (2001). Ekonomi Internasional Teori dan Kebijakan Perdagangan Internasional. Jakarta: Ghalia.

Hinloopen, J., \& Onderstal, S. (2010). Collusion and the choice of auction: An experimental study.

International Pepper Community [IPC]. (2017). Pepper Statistical Yearbook 2017. Jakarta (ID).

International Trade Center [ITC]. (2017). Trade Map Trade Statistic For International Business Development. Retrieved from https://trademap.org.

Kementerian Pertanian. (2015). Outlook Lada : Komoditas Pertanian Subsektor Perkebunan. Pusat Data dan Sistem Informasi Pertanian, Sekretariat Jenderal, Kementerian Pertanian. Jakarta. 
Krugman, P. R., \& Obstfeld, M. (2005). Ekonomi Internasional Teori dan Kebijakan $5^{\text {th }}$ ed. Jakarta: PT. Indeks Kelompok Gramedia.

Kustiari, R., \& Dermoredjo, S. K. (2017). Proteksi tarif optimal untuk kedelai di Indonesia. Jurnal Pertanian Agros, 15(1), 148-159.

Nhien, N. T. H. (2016). The Competitiveness of Vietnamese Coffee Into The EU Market. Centria University of Applied Scinces Finlandia.

Rosiana, N., Nurmalina, R., Winandi, R., \& Rifin, A. (2017). The Level of Comparative Advantages of World Main Coffee Producers. Buletin Ilmiah Litbang Perdagangan, 11(2), 227-246.

Salvatore, D. (1997). Ekonomi Internasional (Terjemahan). Jakarta (ID): Erlangga.

Tambunan, T. (2001). Perekonomian Indonesia: Teori, Temuan dan Empiris. Jakarta: Ghalia.

Utomo, S. (2012). Dampak impor dan ekspor jagung terhadap produktivitas jagung di Indonesia. Etikonomi, 11(2), 158-179. 